\title{
REMOÇÃO DE FÓSFORO DE EFLUENTES DA PARBOILIZAÇÃO DE ARROZ POR ABSORÇÃO BIOLÓGICA ESTIMULADA EM REATOR EM BATELADA SEQUENCIAL (RBS) ${ }^{1}$
}

\author{
Osvaldo Luís Vieira FARIA ${ }^{2, *}$, Paulo Roberto KOETZ ${ }^{3}$, Magda Santos dos SANTOS ${ }^{4}$, Wolney Aliodes NUNES ${ }^{5}$
}

\section{RESUMO}

O efluente do arroz parboilizado contém altas concentrações de fósforo. Um reator em batelada seqüencial (RBS) alimentado com efluente de reator UASB, operou com três fases anaeróbias e aeróbias e tempo de detenção de sólidos (TDS) de 25 d, 15 d, 10 d e $5 \mathrm{~d}$ e tempo de reação $\left(t_{\mathrm{R}}\right)$ de $1 \mathrm{~d}, 2 \mathrm{~d}$ e $3 \mathrm{~d}$ com e sem a adição de ácido acético (HAc). O reator operou com o efluente do equalizador em duas fases tratando com TDS de cinco dias. A eficiência foi calculada pela relação entre a massa de fósforo suspenso descartada e a massa total alimentada. O maior potencial de remoção de 46,14 mg ocorreu operando-se com uma fase anaeróbia e uma aeróbia com adição de HAc. $\mathrm{O} t_{\mathrm{R}}$ de um dia tem a maior possibilidade de aumento da eficiência pelo incremento do descarte de biomassa. A operação com TDS menores obtém as maiores eficiências de remoção. A capacidade de remoção é melhor utilizada com TDS de cinco dias. A maior eficiência $(\mathrm{E}=17,82 \%)$ foi obtida tratando o efluente do reator UASB com TDS de cinco dias, com duas fases, sem a adição HAc.

Palavras-Chave: arroz parboilizado, nutrientes, reator UASB.

\section{SUMMARY}

RICE PARBOILIZATION WASTEWATER PHOSPHORUS REMOVAL BY ENHANCED BIOLOGICAL ASSIMILATION IN SEQUENCING BATCH REACTOR (SBR). The parboiled rice effluent has high phosphorus concentration. A sequential batch reactor (SBR) was fed with a UASB reactor effluent and operated with three anaerobic and aerobic phases and solids retention time (SRT) of $25 \mathrm{~d}$, $15 \mathrm{~d}, 10 \mathrm{~d}$ and $5 \mathrm{~d}$, and reaction time $\left(t_{\mathrm{R}}\right)$ of $1 \mathrm{~d}, 2 \mathrm{~d}$ and $3 \mathrm{~d}$, with and without acetic acid (HOAc) addition. The reactor operated with $5 \mathrm{~d}$ of SRT and two phases treating equalization tank effluent. The removal efficiency was calculated by the relation between phosphorus suspended wasted mass and feed mass. The biggest removal potential, $46.14 \mathrm{mg}$, was operated with HOAc addition and one anaerobic and aerobic phase. The biggest possibility of efficiency increase by biomass waste was obtained with $t_{\mathrm{R}}=1 \mathrm{~d}$. The system operating with smaller SRT achieves higher removal efficiencies. The removal capacity is better utilized with five days of SRT. The highest efficiency ( $E=17.82 \%$ ) was obtained by treating the UASB reactor effluent with two phases, five days of SRT, without HOAc addition.

Keywords: parboiled rice, nutrients, reactor UASB.

\section{1 - INTRODUÇÃO}

A produção mundial de arroz somente é superada pela de trigo [12]. Os líderes em produção estão localizados no Sul, onde predomina o cultivo em terras baixas (várzeas), com rendimento por hectare superando 5 t. A produtividade brasileira é de $2,8 \mathrm{t} / \mathrm{ha}$. O

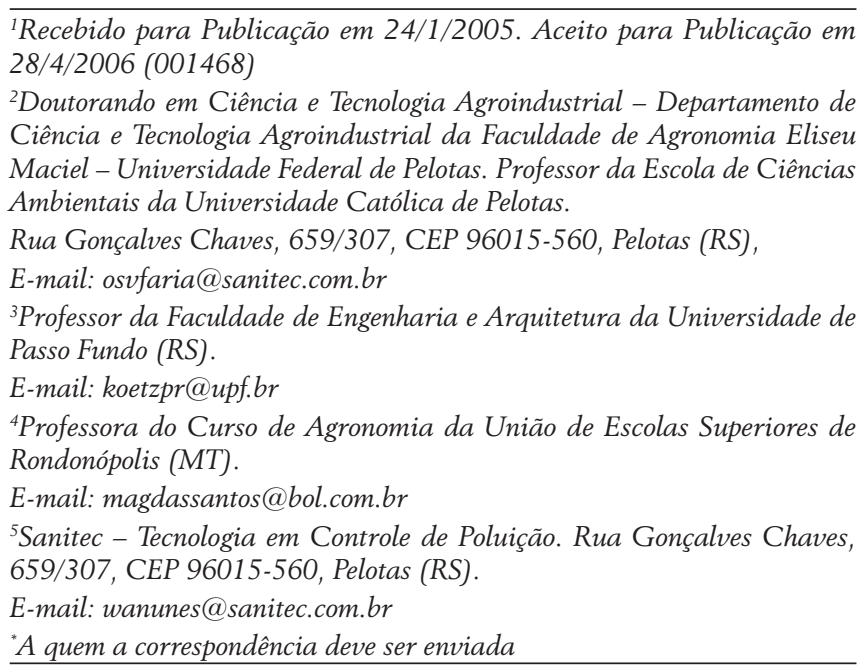

Brasil ocupa a sétima posição no ranking mundial [1]. A produção brasileira de grãos de arroz em 2004 está estimada em 13.356.292 t [6]. Os 14 mil produtores de arroz no Rio Grande do Sul geram a metade de toda a produção nacional [1].

A parboilização do arroz é o processo hidrotérmico, no qual o arroz em casca é imerso em água potável, com temperatura superior a $58^{\circ} \mathrm{C}$, seguido de gelatinização parcial ou total do amido e de secagem [7]. O arroz beneficiado parboilizado apresenta aumentos em valor nutritivo, renda, rendimento e conservabilidade de grãos e dos subprodutos, apresentando cada vez mais importância quantitativa e qualitativa, como processo de beneficiamento de arroz [13]. O arroz parboilizado representa $25 \%$ do total de arroz produzido no Brasil, assim como no resto do mundo [1].

O processo de parboilização gera $4 \mathrm{~L}$ de efluente por quilo de arroz processado [17] apud. [11]. O efluente da parboilização de arroz contém altas cargas de substâncias orgânicas e nutrientes como nitrogênio e fósforo. A concentração de fósforo neste efluente é de 100,0 mg.L-1 [23]. A Tabela 1 apresenta as características físico-químicas do efluente da parboilização de arroz. 
TABELA 1 - Características físico-químicas do efluente da parboilização de arroz

\begin{tabular}{lccc}
\hline Parâmetros (mg.L-1) & Mínimo & Média & Máximo \\
\hline Ácidos voláteis totais & 120,0 & 672,0 & $1.357,0$ \\
Cloretos & 16,0 & 162,7 & 307,0 \\
DBO & $1.600,0$ & $3.200,0$ & $4.580,0$ \\
DQO & $1.898,0$ & $4.536,0$ & $7.809,0$ \\
Fósforo & 34,0 & 100,0 & 143,0 \\
Nitrogênio Amoniacal & 9,6 & 35,0 & 74,4 \\
Nitrogênio total Kjeldahl & 48,0 & 91,0 & 141,0 \\
pH & 3,4 & 5,8 & 7,6 \\
Sólidos suspensos totais & 118,0 & 294,0 & 492,0 \\
Sólidos suspensos voláteis & 94,0 & 249,0 & 428,0 \\
Sulfatos & 51,0 & 141,0 & 202,0 \\
\hline Fonte: Laboratório de Controle de Poluição - DCTA - FAEM - UFPEL, citado por [24]
\end{tabular}

O fósforo provém dos resíduos de adubação, defensivos agrícolas e da hidrólise da fitina, substância presente nas cascas dos grãos que, hidrolisada no encharcamento, libera o fósforo como fosfato [5] apud. [23]. O fósforo nos cereais apresenta-se de 70\% a 75\% na forma de ácido fítico. O ácido fítico é o ácido inositol hexafosfórico (Figura 1) e a fitase o transforma em inositol e ácido fosfórico livre. A fitase é uma esterase que hidrolisa o ácido fítico [14].

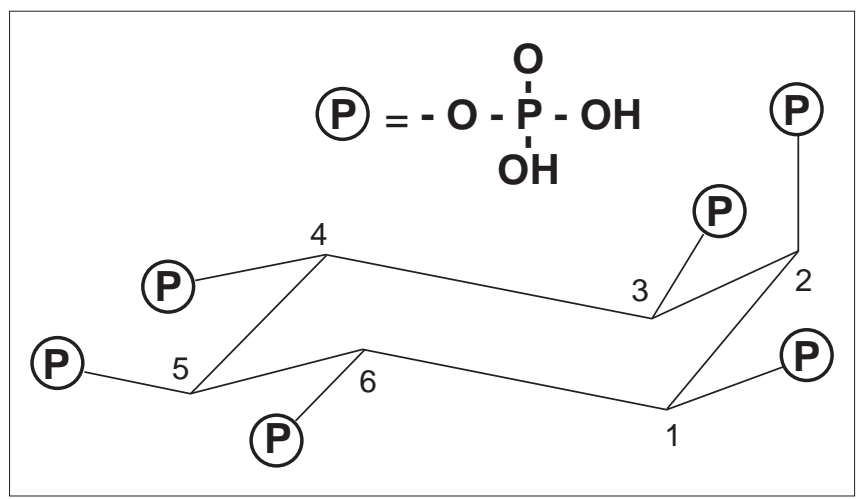

FIGURA 1 - Estrutura do ácido fítico

O fósforo associado à disponibilidade de nutrientes nitrogenados, estimula o crescimento de macro e microorganismos fotossintetizadores causando a eutrofização em corpos hídricos [19], [4] apud. [16].

A concentração máxima de fósforo em efluentes a ser lançada num corpo d'água é de 1,0 mg.L $\mathrm{L}^{-1}$ de P [22]. Segundo dados da Fundação Estadual de Proteção Ambiental do RS (Fepam), entre 1994 e 2000, 11\% das indústrias nunca atenderam ao padrão de emissão de fósforo, $78 \%$ às vezes e outros $11 \%$ sempre atendem [9] apud. [16].

O uso do reator Upflow Anaerobic Sludge Blanket (UASB) tem grande vantagem como um sistema de prétratamento, com tratamento complementar em sistemas convencionais como lagoas de estabilização ou sistemas de lodo ativado. A digestão anaeróbia não remove microorganismos patogênicos e nutrientes [15].

A remoção de matéria orgânica e nitrogênio é executada por algumas tecnologias consolidadas, como reatores anaeróbios e lodos ativados. A concentração de até $100 \mathrm{mg} . \mathrm{L}^{-1}$ de fósforo (P) impossibilita a remoção por processos biológicos simples. Os processos físico-químicos de remoção de fósforo são descrições de literatura em escala de bancada e de planta piloto e os problemas associados a estes tratamentos são a alta quantidade de lodo gerado e o uso de reagentes químicos em grande quantidade [16].

O reator em batelada seqüencial (RBS) é um sistema de carga e descarga. Os processos unitários e bioquímicos são realizados no mesmo tanque em seqüência [18]. Na remoção biológica de nutrientes, os ciclos são constituídos de fases que possuem condições anóxicas, anaeróbias e aeróbias [20] apud. [23].

Um período prolongado de pré-condicionamento anaeróbio estimulará a acumulação microbiana de fósforo na fase aeróbia [2]. Os sistemas biológicos estimulados para remoção de fósforo (SBERF) são uma tecnologia eficiente [8]. O princípio básico de um SBERF é a colocação de uma zona anaeróbia seguida de uma zona aeróbia alimentandose o efluente na zona anaeróbia. Os SBERF são largamente utilizados em toda a parte do mundo e têm a vantagem econômica da baixa produção de lodo e o menor uso de produtos químicos [19].

A zona anaeróbia, se há substrato orgânico disponível, atua como um seletor biológico aumentando a população de bactérias acumuladoras de fósforo (polifosfato), suprimindo o crescimento de microorganismos filamentosos [21]. O mecanismo da remoção biológica de fósforo se constitui das fases de fermentação e estocagem de ácidos graxos voláteis na fase anaeróbia e absorção de fósforo para produção de novas células e manutenção na fase aeróbia [23].

O fósforo é liberado das células das bactérias removedoras de fósforo, em meio anaeróbio, absorvendo carbono e o transformando em polihidroxibutirato (PHB), que é armazenado no interior da célula. O PHB é liberado em meio aeróbio na forma de energia e o fosfato é absorvido pelas bactérias. O processo de remoção de fósforo necessita, de fonte de carbono, compostos de baixo peso molecular, como o ácido acético e o ácido propiônico. A remoção biológica de fósforo envolve a sua incorporação na biomassa como material celular. A retirada de fósforo do sistema se dá através da purga da biomassa [25] apud. [23].

As bactérias poli-P são definidas como microorganismos capazes de absorver fósforo em excesso do requerido para o crescimento celular. Uma seqüência anaeróbia-aeróbia é requerida para que seja estabelecida uma população de bactérias poli-P num sistema biológico [21]. Os organismos acumuladores de polifosfato (OAP) representam um significativo papel na remoção de fósforo. Os primeiros microorganismos isolados de um SBERF foram espécies Acinetobacter [19]. Revisões da microbiologia de SBERF 
indicam que há uma diversidade de organismos envolvidos na acumulação Poli-P [26]. As bactérias da espécie Rhodocylus também estão envolvidas na remoção de fósforo [10] apud. [19]. A taxa de decaimento de organismos Poli-P é muito menor do que as bactérias aeróbias heterotróficas comuns em tratamento de efluentes. A constante de decaimento das bactérias poli-P é de $0,04 \mathrm{~d}^{-1}$ a $20^{\circ} \mathrm{C}$ contra $0,24 \mathrm{~d}^{-1}$ dos microorganismos normais [26].

A fração das bactérias poli-P é determinada pela fração de substrato obtida na fase anaeróbia, a qual será determinada pelo que é limitante, substrato ou fósforo disponível. A fração de bactérias poli-P resultante é determinada pela relação substrato disponível pelo fósforo disponível na fase anaeróbia. O tipo dos compostos orgânicos na fase anaeróbia é também importante. Eles devem ser solúveis, como os ácidos voláteis totais (AVT) de cadeia curta, os quais as bactérias poli-P podem absorver para dentro da célula e polimerizar. Os compostos orgânicos disponíveis não são completamente removidos no estágio anaeróbio e passarão ao estágio aeróbio se o fósforo é limitante. A remoção de fósforo é limitada se a DQO disponível é limitante. A eficiência do processo poderá ser aumentada pela pré-fermentação ou pela adição de compostos orgânicos a fim de aumentar a DQO disponível, ou precipitação química do fósforo excedente. O sistema biológico é dominado pelas bactérias poli-P, e o percentual de $\mathrm{P}$ nos sólidos suspensos voláteis (SSV) é alto, se a DQO for limitante [21].

O tempo de detenção de sólidos (TDS) representa o período médio no qual o lodo permanece no sistema. O TDS é o principal parâmetro de projeto de um sistema biológico, o qual determina o volume do tanque, o volume de lodo descartado e as necessidades de oxigênio. O TDS é mantido pelo descarte do excesso de lodo produzido. O processo pode ser controlado pelo descarte de um volume igual ao do reator dividido pelo TDS [18].

Os sistemas SBERF são pouco afetados pelo TDS numa faixa de dois dias a quarenta dias. Este fenômeno pode ser atribuído à baixa taxa de decaimento endógeno das bactérias poli-P. As bactérias poli-P representam grande parte da biomassa para longos TDS. A capacidade máxima de estocagem de $\mathrm{P}$ pode ser usada para explicar porque a performance de um SBERF é independente do TDS. Quando o TDS é aumentado (o descarte de lodo é diminuído), a percentagem de $\mathrm{P}$ aumenta até um valor máximo e a remoção de $\mathrm{P}$ muda pouco. Os SBERF são relativamente insensíveis a mudanças de temperatura. A razão DQO/P, no efluente, também influencia os efeitos da temperatura num SBERF. Os mecanismos de SBERF podem operar na faixa de 8,5 a 9,0 [21].

O objetivo do trabalho foi determinar as condições de operação de um SBERF para o efluente da parboilização de arroz pelo estudo do efeito do número de fases anaeróbias e aeróbias por ciclo de tratamento em batelada seqüencial, o efeito da relação $\mathrm{C} / \mathrm{P}$, o efeito da adição de fonte externa de carbono e a influência do tempo de detenção de sólidos.

\section{2 - MATERIAL E MÉTODOS}

\section{1 - Material}

O experimento foi realizado no Laboratório de Controle de Poluição (LCP-DCTA-FAEM-UFPEL). O reator em batelada seqüencial (RBS) foi construído em vidro borossilicato com 104 mm de diâmetro e volume total de 2,62 L, com dispositivos de alimentação e descarga, de agitação, de aeração e de controle de temperatura. Os tempos de carga, descarga, agitação e aeração foram controlados por um Controlador Lógico Programável (CLP) Siemens (Figura 2).

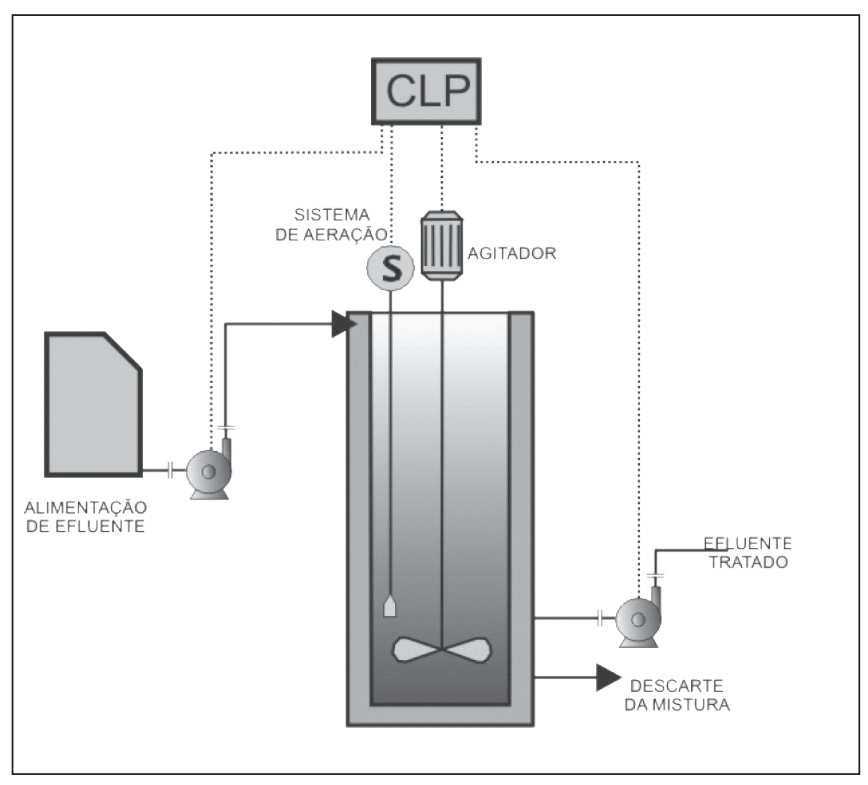

FIGURA 2 - Esquema do reator piloto

\section{2 - Métodos}

A alimentação, a mistura e a descarga foram analisadas duas vezes por semana para os seguintes parâmetros: fósforo total e fósforo solúvel [3]. Foram monitorados os parâmetros: oxigênio dissolvido (OD), pH e temperatura. $\mathrm{O}$ pH da alimentação foi ajustado para 8,0.

A massa de fósforo foi calculada de acordo com a Equação (1):

$$
m_{p}=V x C_{p}
$$

Sendo:

$m_{\mathrm{P}}$ - Massa de Fósforo (mg)

$\mathrm{C}_{\mathrm{P}}$ - Concentração de fósforo (mg. $\left.\mathrm{L}^{-1}\right)$

$V$ - Volume (L)

O balanço de massa foi elaborado de acordo com o esquema da Figura 3. 


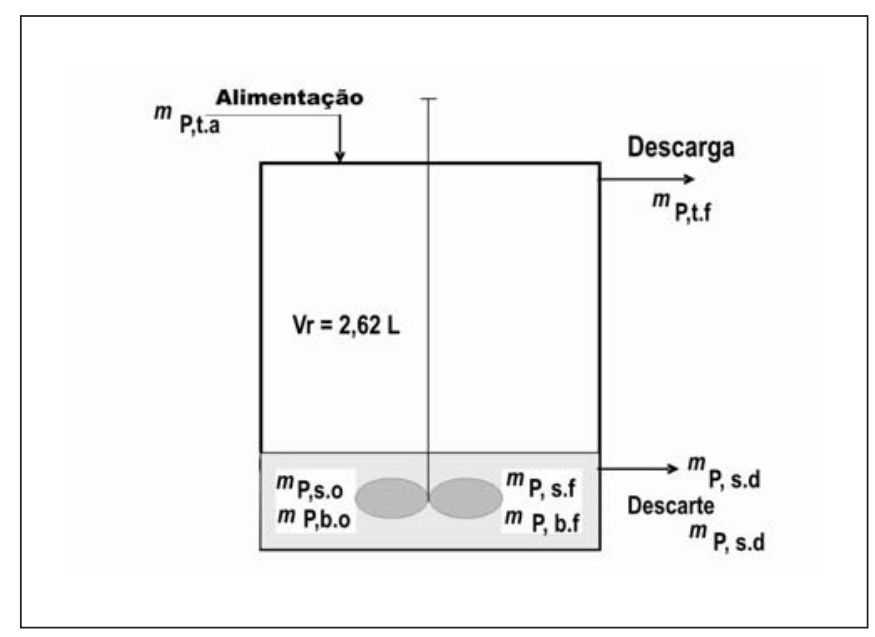

FIGURA 3 - Balanço de massa do RBS. $m_{\mathrm{Pta}}$ - Fósforo total na alimentação; $m_{\mathrm{Pff}}-$ Fósforo total na descarga; $m_{\mathrm{Ps} . \mathrm{d}}-$ Fósforo solúvel no descarte; $m_{\mathrm{Pp.d}}$ - Fósforo suspenso no descarte; $m_{\text {Ps.o }}$ - Fósforo solúvel inicial na biomassa; $m_{\text {Ps.f }}$ - Fósforo solúvel final na biomassa; $m_{\mathrm{Pb} . o}$ - Fósforo inicial na biomassa; $m_{\mathrm{Pb} . \mathrm{f}}$ - Fósforo final na biomassa; Vr - Volume do reator

O balanço de massa foi feito de acordo com a Equação (2).

$$
\Delta m_{\mathrm{Pb}}=m_{\mathrm{P}, \mathrm{t.a}}-\Delta m_{\mathrm{Ps}}-\left(m_{\mathrm{P}, \mathrm{s} . \mathrm{d}}+m_{\mathrm{P}, \mathrm{p} . \mathrm{d}}\right)-m_{\mathrm{P}, \mathrm{t.f}}
$$

\section{Sendo:}

$m_{\text {P, t.a }}$ - Massa de Fósforo total na alimentação (mg)

$\Delta m_{\mathrm{Ps}}$ - Variação da massa de fósforo solúvel na biomassa (mg)

$\Delta m_{\mathrm{Pb}}$ - Variação da massa de fósforo na biomassa (mg)

$$
m_{\text {P, s.d }} \text { - Massa de Fósforo solúvel no descarte (mg) }
$$$$
m_{\text {P, p.d }}-\text { Massa de Fósforo suspenso no descarte (mg) }
$$$$
m_{\mathrm{P}, \mathrm{t.f}}-\text { Massa de Fósforo total na descarga (mg) }
$$

O cálculo usual de eficiência de remoção, que relaciona a diferença entre as concentrações de alimentação e descarga e a concentração de alimentação, não representa, com precisão, a qualidade do processo. A eficiência de remoção foi calculada segundo Equação (3):

$$
E=\frac{m_{P, p . d}}{m_{P, t . a}} \times 100 \%
$$

O tempo de detenção de sólidos foi calculado de acordo com a Equação (4).

$$
T D S=\frac{V_{r}}{V_{d}}
$$

Sendo:

TDS - Tempo de detenção celular (d)

$V_{\mathrm{r}}$ - Volume do reator (L)

$V_{\mathrm{d}}$ - Volume de mistura descartado (L)

O potencial de remoção ( $\left.m_{\mathrm{Ps} \text {, máx }}\right)$ é definido como a soma da variação da massa de fósforo na biomassa e o fósforo suspenso descartado (Equação 5)

$$
m_{\mathrm{Ps}, \text { máx. }}=\Delta m_{\mathrm{Pb}}+m_{P, p . d}(\mathrm{mg})
$$

A taxa de utilização $\left(\tau_{u}\right)$, definida como a razão entre o fósforo suspenso descartado e o fósforo particulado total, foi calculada de acordo com a Equação (6)

$$
\tau_{u}=\frac{m_{P, p . d}}{\left(\Delta \mathrm{mB}+\mathrm{M}_{P, p . d}\right)} x 100 \%
$$

Os sistemas operaram em ciclos constituídos das seguintes fases: Alimentação, agitação anaeróbia, agitação com aeração, descarte e sedimentação. O ciclo foi definido como o período entre a carga e a descarga. O tempo de sedimentação foi de 30 minutos. O decantado serviu como inóculo do ciclo seguinte.

O tempo de reação foi calculado de acordo com a Equação (7).

$$
t_{R}=t_{C}
$$

Sendo:

$t_{\mathrm{R}}$ - Tempo de Reação (h)

$t_{\mathrm{C}}$ - Tempo de um ciclo completo (carga-descarga) (h)

\section{3 - Experimento 1 - efeito do número de fases e da adição de ácido acético}

\subsection{1 - Material}

O efluente foi proveniente da descarga do reator UASB da estação de tratamento de efluentes de uma indústria de parboilização (Figura 4).

\subsection{2 - Métodos}

O experimento 1 operou com ciclo de $24 \mathrm{~h}$. O primeiro tratamento (1a) com três fases anaeróbias e três fases aeróbias intercaladas, sendo a primeira fase anaeróbia de $3 \mathrm{~h}$ e as demais fases com duração de $4 \mathrm{~h}$ cada uma (Figura 5). No segundo tratamento (1b), com as mesmas fases do tratamento 1a (Figura 5), foi adicionado ácido acético (HAc) como fonte de carbono na relação 10:1 AVT: $\mathrm{P}(\mathrm{m} / \mathrm{m})$. O terceiro tratamento (1c) teve uma fase anaeró- 


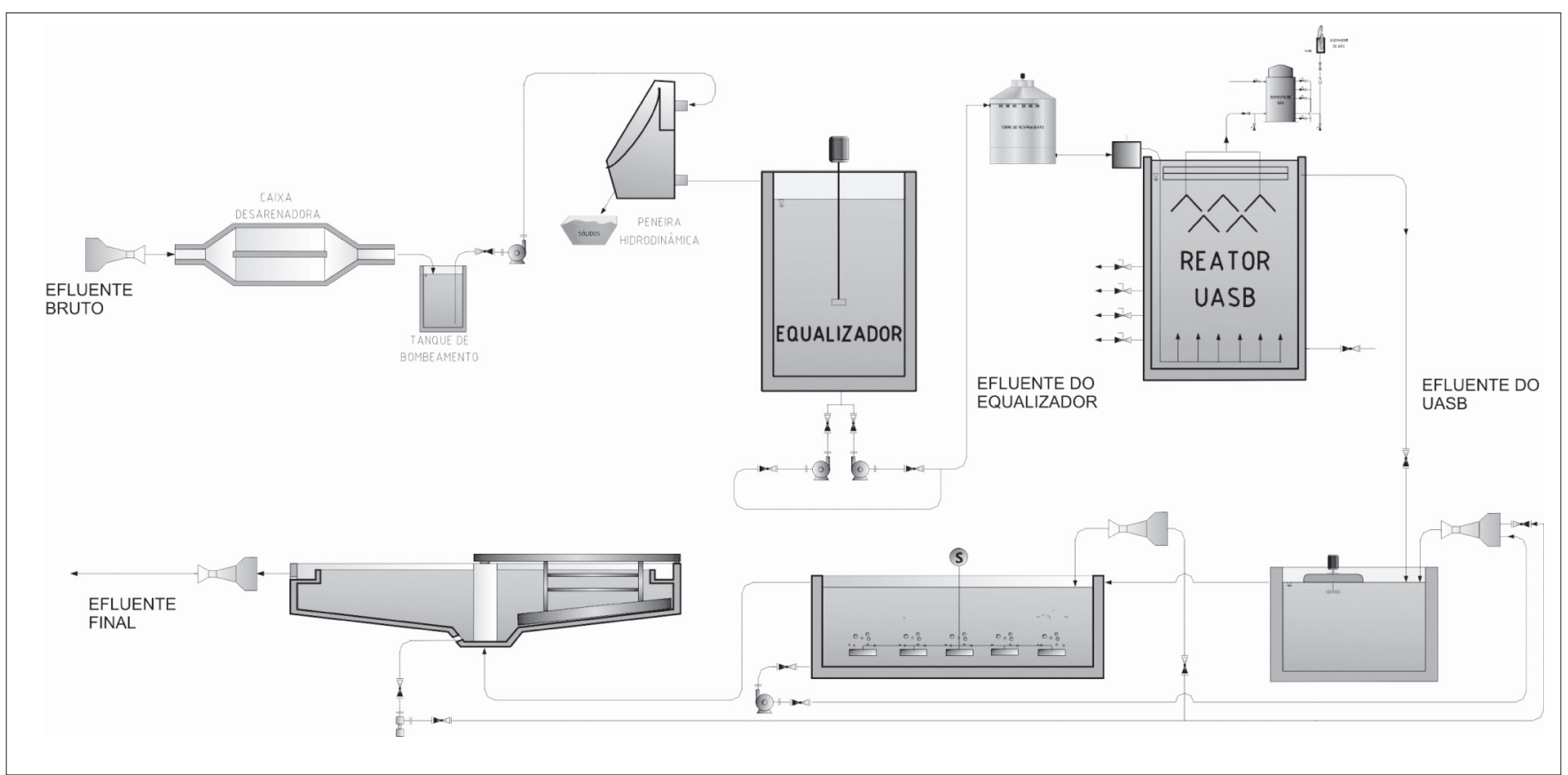

FIGURA 4 - Esquema da estação de tratamento de efluente industrial

bia de 9 h e 30 min seguida de uma fase aeróbia de 13 h e 30 min (Figura 6). No quarto tratamento (1d), com as mesmas fases do tratamento 1c (Figura 6), foi adicionado diariamente à alimentação o HAc como fonte de carbono na relação 10:1 AVT:P $(\mathrm{m} / \mathrm{m})$.

A partida dos reatores foi feita com uma biomassa aeróbia proveniente de um reator RBS operando nas mesmas condições do experimento, com $3.000 \mathrm{mg} . \mathrm{L}^{-1}$ de SSV. O sistema foi operado a uma temperatura de $20^{\circ} \mathrm{C} \pm 5^{\circ} \mathrm{C}$. A concentração de oxigênio dissolvido (OD) foi de 5,8 mg. $\mathrm{L}^{-1}$. O tempo de detenção de sólidos foi mantido em 25 dias pelo descarte da mistura.

\section{4 - Experimento 2 - efeito do tempo de reação}

\subsection{1 - Métodos}

O segundo experimento operou com três tempos de reação constituídos de três fases anaeróbias e três fases

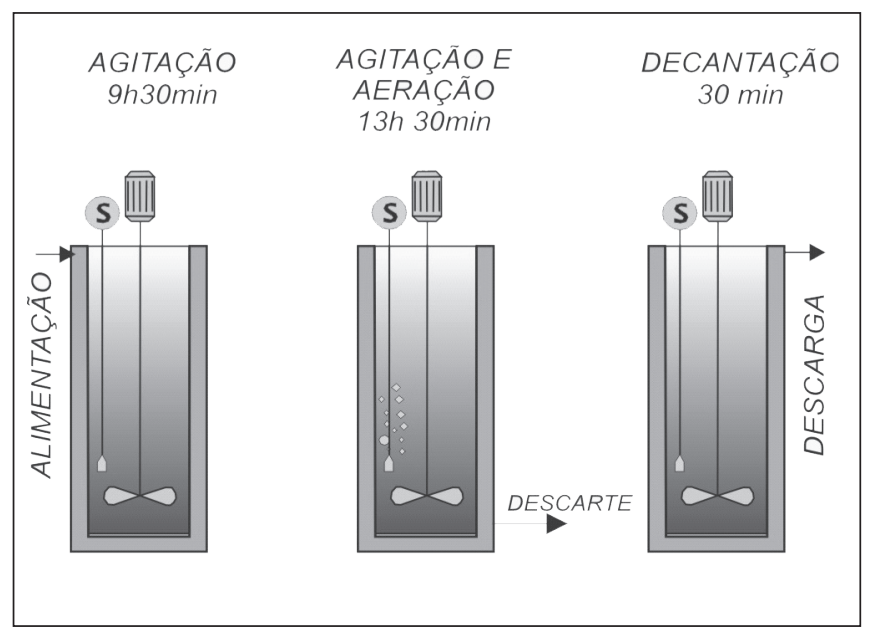

FIGURA 6 - Fases de operação do reator seqüencial em batelada (experimento $1 \mathrm{~b}$ ) operando com uma fase anaeróbia e uma fase aeróbia

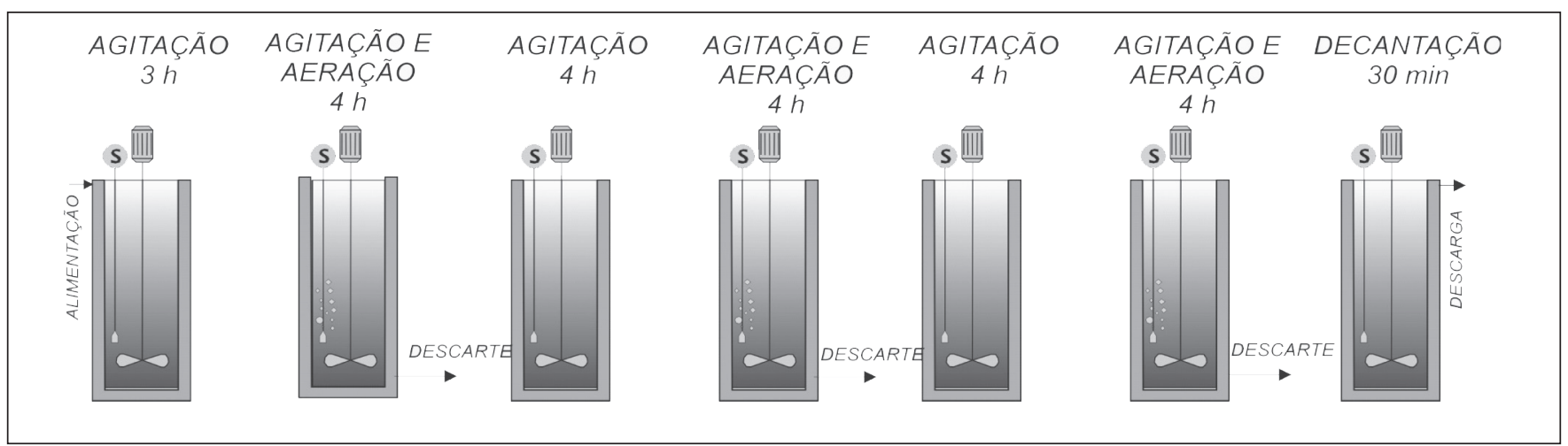

FIGURA 5 - Fases de operação do reator seqüencial em batelada (experimento 1a) operando com três fases anaeróbias e três fases aeróbias 
aeróbias por dia sendo a primeira fase anaeróbia de $3 \mathrm{~h}$ e as demais fases com duração de $4 \mathrm{~h}$ cada uma, em três tratamentos ( $2 \mathrm{a}, t_{\mathrm{R}}=1 \mathrm{dia} ; 2 \mathrm{~b}, t_{\mathrm{R}}=2$ dias; $2 \mathrm{c}, t_{\mathrm{R}}=3$ dias), Equação 7. O ácido acético foi adicionado diariamente à alimentação na relação 10:1 AVT:P $(\mathrm{m} / \mathrm{m})$.

A partida dos reatores foi feita com a biomassa aeróbia proveniente do experimento anterior. O sistema foi operado a uma temperatura de $20^{\circ} \mathrm{C} \pm 5^{\circ} \mathrm{C}$. A concentração de $\mathrm{OD}$ foi de $6,9 \mathrm{mg} . \mathrm{L}^{-1}$ no tratamento $2 \mathrm{a}$, de $7,2 \mathrm{mg} . \mathrm{L}^{-1}$ no tratamento $2 \mathrm{~b}$ e, de $6,9 \mathrm{mg} . \mathrm{L}^{-1}$ no tratamento $2 \mathrm{c}$. O TDS foi mantido em 25 dias pelo descarte da mistura.

\section{5 - Experimento 3 - efeito do tempo de detenção de sólidos}

\subsection{1 - Métodos}

O experimento 3 operou com um ciclo de 24 h constituído de três fases anaeróbias e três fases aeróbias (Figura 7) em quatro tratamentos ( $3 \mathrm{a}, \mathrm{TDS}=25$ dias; $3 \mathrm{~b}, \mathrm{TDS}=15$ dias; $3 \mathrm{c}, \mathrm{TDS}=10$ dias; $3 \mathrm{~d}, \mathrm{TDS}=5$ dias). $\mathrm{O}$ ácido acético foi adicionado diariamente à alimentação na relação 10:1 AVT:P $(m / m)$.

A partida dos reatores foi feita com a biomassa aeróbia proveniente do experimento anterior. O sistema foi operado a uma temperatura de $20^{\circ} \mathrm{C} \pm 5^{\circ} \mathrm{C}$. A concentração de OD foi de 6,4 mg. $\mathrm{L}^{-1}$ no tratamento $3 \mathrm{a}$, de $6,5 \mathrm{mg} . \mathrm{L}^{-1}$ no tratamento $3 \mathrm{~b}$, de 7,4 mg. $\mathrm{L}^{-1}$ no tratamento $3 \mathrm{c}$ e de 8,2 mg. $\mathrm{L}^{-1}$ no tratamento $3 \mathrm{~d}$. O tempo de detenção de sólidos foi mantido pelo descarte da mistura.

\section{6 - Experimento 4 - efeito das características do efluente}

\subsection{1 - Material}

O efluente do primeiro tratamento foi proveniente da descarga do reator UASB (Figura 4) com as seguintes relações: $\mathrm{DQO} / \mathrm{P}=31,79$ e $\mathrm{AVT} / \mathrm{P}=6,48$. O efluente do segundo tratamento foi proveniente do equalizador (Figura 4) com as relações: $\mathrm{DQO} / \mathrm{P}=5,91$ e $\mathrm{AVT} / \mathrm{P}=1,53$.

\subsection{2 - Métodos}

O experimento 4 operou com um ciclo constituído de uma fase anaeróbia de $2 \mathrm{~h}$ e uma fase aeróbia de 5 h ( $\mathrm{Fi}$ gura 8) em dois tratamentos: Alimentação com Efluente do UASB (4a); Alimentação com o Efluente do equalizador (4b) (Figura 4).

O descarte foi realizado $15 \mathrm{~min}$ antes do final da fase aeróbia. A partida dos reatores foi feita com uma biomassa aeróbia proveniente de um reator biológico aerado industrial, com $1.800 \mathrm{mg} . \mathrm{L}^{-1}$ de SSV. O sistema foi operado a uma temperatura de $20^{\circ} \mathrm{C} \pm 1^{\circ} \mathrm{C}$. A concentração de OD foi de 5,50 mg. $\mathrm{L}^{-1}$ no reator tratando o efluente do UASB e $2,96 \mathrm{mg} . \mathrm{L}^{-1}$ no reator tratando o efluente do equalizador. $\mathrm{O}$ tempo de detenção de sólidos foi mantido em 5 dias pelo descarte da mistura. A alimentação, a mistura e a descarga foram analisadas duas vezes por semana durante 90 dias.

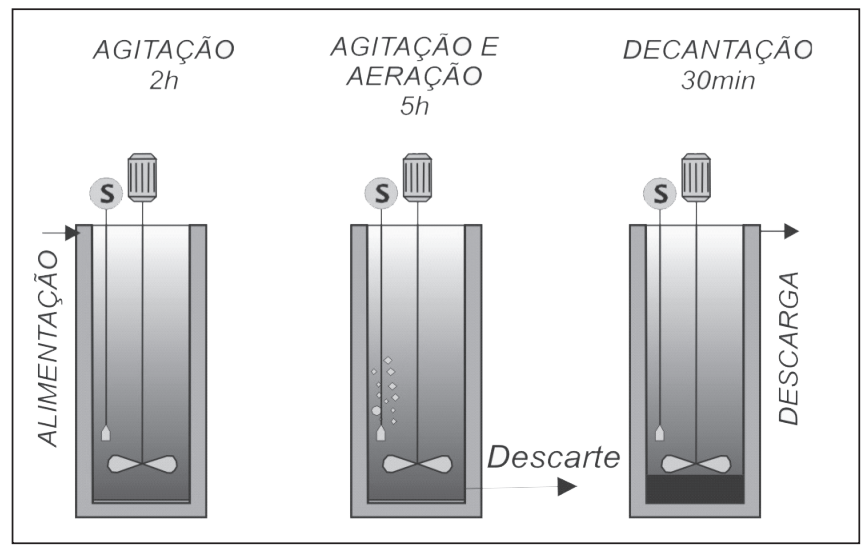

FIGURA 8 - Fases de operação do RBS no experimento 4

\section{3 - RESULTADOS E DISCUSSÃO}

O balanço de massa (Equação 2) do experimento 1, tratamento la mostra que a massa de fósforo (Equação 1) absorvida pela biomassa e descartada $\left(m_{\text {P.p.d }}\right)$ foi de 32,03 mg para uma alimentação $\left(m_{\text {p.t.a }}\right)$ de $189,31 \mathrm{mg}$ de fósforo. Para o tratamento $1 \mathrm{~b}$, a $m_{\text {P,p.d }}$ foi de $21,18 \mathrm{mg}$ para $m_{\mathrm{P} \text {, }}$ t.a $=221,2 \mathrm{mg}$ (Figura 9).

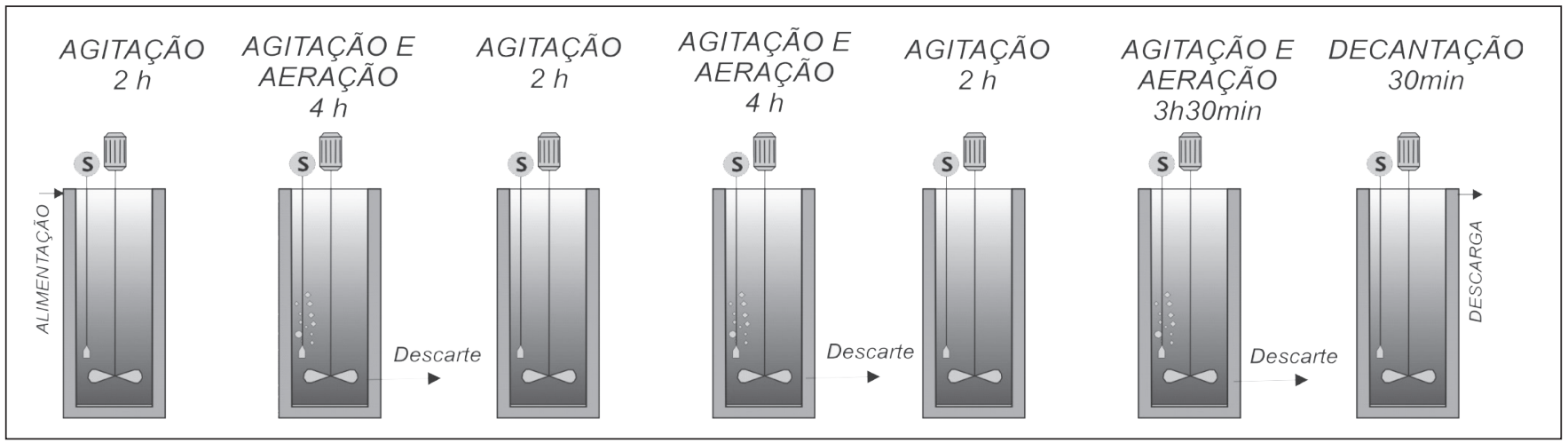

FIGURA 7 - Fases de operação do RBS operando com três fases anaeróbias e três fases aeróbias 


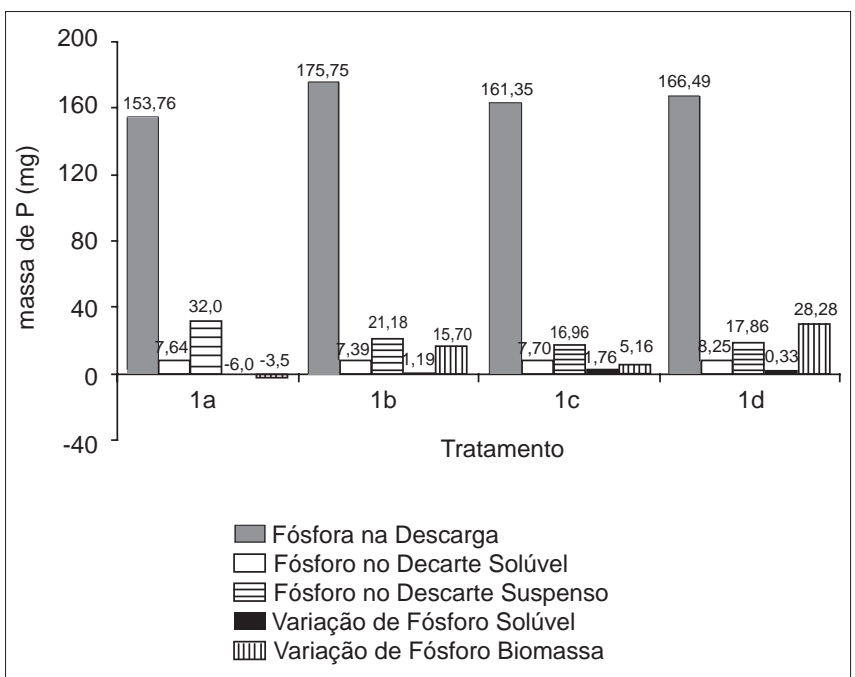

FIGURA 9 - Balanço de massa do RBS tratando o efluente do reator UASB de uma indústria de parboilização, operando com três fases anaeróbias e três fases aeróbias sem HAc(1a) e com HAc (1b) e uma fase anaeróbia e uma fase aeróbia sem HAc (1c) e com a adição de HAc (1d)

O balanço de massa para o tratamento 1c mostra que a $m_{\text {P.p.d }}$ foi de $16,96 \mathrm{mg}$ para $m_{\text {P.t.a }}$ de 192,92 $\mathrm{mg}$; para o tratamento $1 \mathrm{~d}$ a $m_{\text {P, p.d }}$ foi de $17,86 \mathrm{mg}$ para $m_{\text {p.t.a }}$ de 221,2 mg (Figura 9).

TABELA 2 - Valores de Eficiência de remoção (E), taxa de utilização $\left(\tau_{\mathrm{u}}\right)$ e potencial de remoção $\left(m_{\mathrm{Ps} \text {, máx }}\right)$ do experimento tratando o efluente do reator UASB de uma indústria de parboilização, operando com três fases anaeróbias e três fases aeróbias sem HAc (1a) e com HAc (1b) e uma fase anaeróbia e uma fase aeróbia sem HAc (1c) e com a adição de HAc (1d)

\begin{tabular}{cccc}
\hline Tratamento & $\mathrm{E} \mathrm{( \% )}$ & $\tau_{\mathrm{u}}(\%)$ & $\boldsymbol{m}_{\mathrm{Ps}, \max }(\mathbf{m g})$ \\
\hline 1a & 16,92 & 112,29 & 28,53 \\
1b & 9,57 & 57,43 & 36,87 \\
1c & 8,79 & 76,68 & 22,11 \\
1d & 8,07 & 38,70 & 46,14 \\
\hline
\end{tabular}

O valor negativo de $-3,51 \mathrm{mg}$ da variação de fósforo na biomassa $\left(\Delta m_{\mathrm{Pb}}\right)$ e a taxa de utilização $\left(\tau_{\mathrm{u}}\right)$ de 112,29 \% (Tabela 2) para o tratamento 1a, indicam que um incremento de descarte de biomassa não resultaria em aumento da remoção de fósforo. Os valores positivos de $\Delta m_{\mathrm{Pb}}$ indicam que um maior descarte de lodo (diminuição do TDS) poderia aumentar o fósforo removido (Figura 9). O tratamento $1 \mathrm{~d}$, apesar da menor eficiência $(\mathrm{E})$, tem o maior $m_{\text {Ps,máx }}$ do experimento (Tabela 2). O tratamento $1 \mathrm{~d}$ tem a maior possibilidade de aumento da eficiência pelo incremento do descarte de biomassa.

O balanço de massa do experimento 2 para $m_{\text {P.t.a }}$ de $162,88 \mathrm{mg}$ para o tratamento $2^{\mathrm{a}}$, indica que a $m_{\text {P.p.d }}$ foi de $3,43 \mathrm{mg}$; para o tratamento $2 \mathrm{~b}$, foi de $9,18 \mathrm{mg}$ e para o tratamento 2c, foi de 7,21 mg (Figura 10).

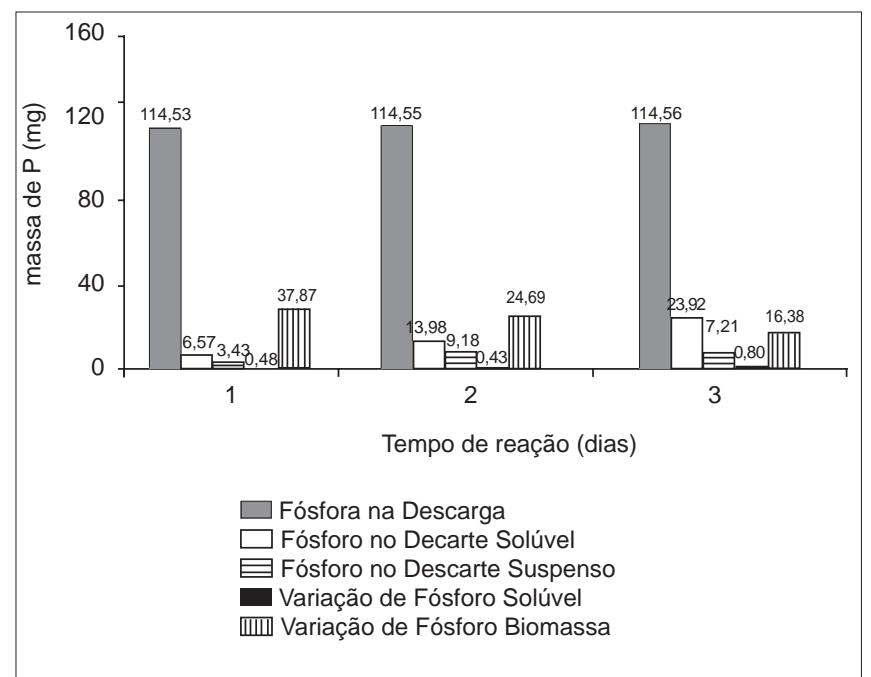

FIGURA 10 - Balanço de massa do RBS tratando o efluente do reator UASB de uma indústria de parboilização, operando com três fases anaeróbias e três fases aeróbias com a adição de HAc em função do tempo de reação

TABELA 3 - Valores de eficiência de remoção (E), taxa de utilização $\left(\tau_{\mathrm{u}}\right)$ e potencial de remoção $\left(m_{\mathrm{Ps} \text {, maxx }}\right)$ do experimento tratando o efluente do reator UASB de uma indústria de parboilização, operando com três fases anaeróbias e três fases aeróbias com HAc para $t_{\mathrm{R}}=1$ dia (tratamento $2 \mathrm{a}$ ), para $t_{\mathrm{R}}=2$ dias (tratamento $2 \mathrm{~b}$ ) e para $t_{\mathrm{R}}=3$ dias (tratamento $2 \mathrm{c}$ )

\begin{tabular}{cccc}
\hline Tratamento & $\mathbf{E ~ ( \% )}$ & $\tau_{\mathrm{u}}(\%)$ & $\boldsymbol{m}_{\mathrm{Ps}, \text { max }}(\mathbf{m g})$ \\
\hline 2a & 2,11 & 8,31 & 41,30 \\
2b & 5,64 & 27,10 & 33,88 \\
2c & 4,43 & 30,58 & 23,58 \\
\hline
\end{tabular}

O tratamento $2 \mathrm{a}$, de menor eficiência (E), tem o maior $m_{\text {Ps, máx }}$ do experimento (Tabela 3). O tratamento 2 a tem a maior possibilidade de aumento da eficiência pelo incremento do descarte de biomassa.

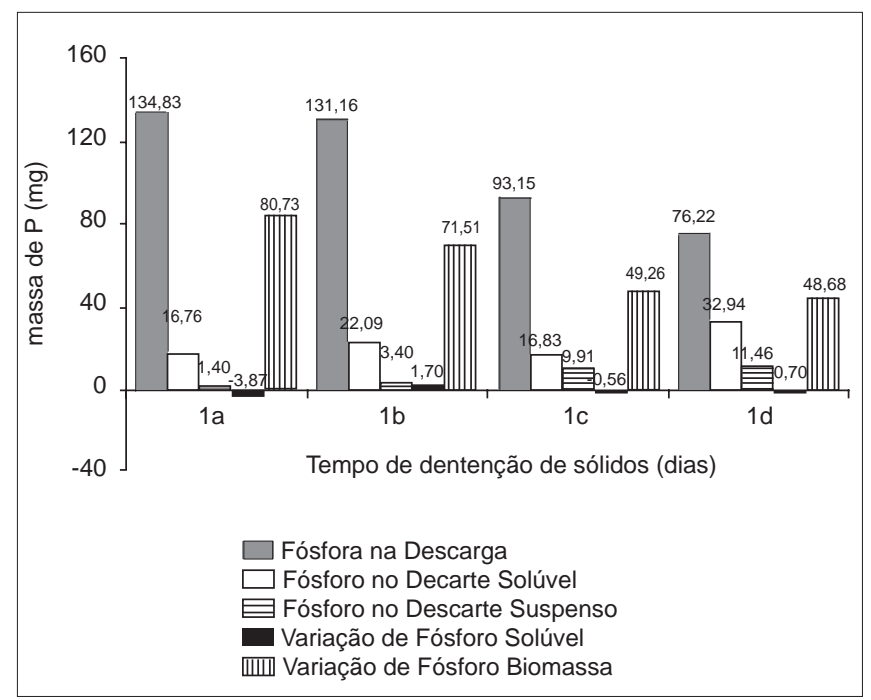

FIGURA 11 - Balanço de massa do RBS tratando o efluente do reator UASB de uma indústria de parboilização, operando com três fases anaeróbias e três fases aeróbias com a adição de HAc em função do tempo de detenção de sólidos 
O balanço de massa do experimento 3 mostra que para $m_{\text {P.t.a }}$ de $229,86 \mathrm{mg}, m_{\text {P.p.d }}$ foi de $1,40 \mathrm{mg}$ para o tratamento $3 \mathrm{a}$ e de $3,40 \mathrm{mg}$ para o tratamento $3 \mathrm{~b}$. Para uma $m_{\text {p.t.a }}$ de $168,60 \mathrm{mg}$, a $m_{\text {Pp.d }}$ foi de 9,91 mg para o tratamento $3 \mathrm{c}$ e de $11,46 \mathrm{mg}$ para o tratamento $3 \mathrm{~d}$.

TABELA 4 - Valores de eficiência de remoção (E), taxa de utilização $\left(\tau_{\mathrm{u}}\right)$ e potencial de remoção $\left(m_{\mathrm{Ps} \text {, máx }}\right)$ do experimento tratando o efluente do reator UASB de uma indústria de parboilização, operando com três fases anaeróbias e três fases aeróbias com HAc para TDS $=25$ dias (tratamento $3 \mathrm{a}$ ), TDS $=15$ dias (tratamento $3 \mathrm{~b}$ ), TDS $=10$ dias (tratamento $3 \mathrm{c}$ ) e TDS=5 dias (tratamento $3 \mathrm{~d}$ )

\begin{tabular}{cccc}
\hline Tratamento & $\mathbf{E ~ ( \% )}$ & $\tau_{\mathrm{u}}(\%)$ & $\boldsymbol{m}_{\mathrm{Ps}, \text { máx }}(\mathbf{m g})$ \\
\hline 3a & 0,61 & 1,70 & 82,13 \\
3b & 1,48 & 4,54 & 74,91 \\
3c & 5,88 & 16,75 & 59,18 \\
3d & 6,80 & 19,06 & 60,14 \\
\hline
\end{tabular}

Os valores de $m_{\mathrm{Ps} \text { máx }}$ mostram que um descarte maior de lodo poderá aumentar a remoção de fósforo para os quatro tratamentos (Tabela 4). O valor crescente da taxa de utilização $\left(\tau_{\mathrm{U}}\right)$ com a diminuição do TDS, indica que para menores TDS é possível remover uma parcela maior do fósforo particulado.

A diminuição do TDS mostra um aumento de eficiência do processo. Este aumento não é proporcional à diminuição do TDS, provavelmente devido aos sistemas de menor idade do lodo (TDS) ter uma menor fração de organismos poli-P. Isto pode ser explicado pelo fato da taxa de decaimento de organismos Poli-P ser muito menor do que de bactérias normais de sistemas aeróbios [26]. O fósforo pode ser acumulado na biomassa de duas formas: pelo crescimento da biomassa; pelo aumento do teor de fósforo estocado pelos microorganismos. O fósforo acumulado por crescimento pode ser removido pelo aumento do volume descartado (diminuição do TDS). O fósforo acumulado na biomassa, devido ao aumento da fração de bactérias poli-P nos SSV [21], tem a remoção limitada à estabilidade do sistema.

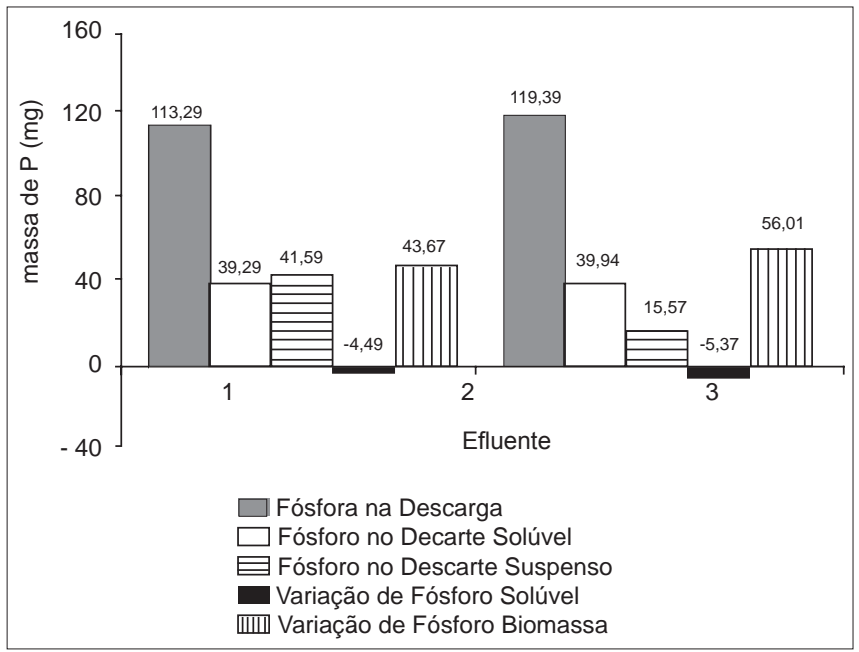

FIGURA 12 - Balanço de massa do RBS tratando o efluente do reator UASB e do equalizador, operando com uma fase anaeróbia e uma fase aeróbia
O balanço de massa do experimento 4 para uma $m_{\text {p.t.a }}$ de 225,54 mg no tratamento 4a (Figura 4), indica que $m_{\mathrm{P}, \mathrm{p} \text {. }}$ d foi de 15,57 mg, para o tratamento 4b (Figura 4), mostra que a $m_{\text {p.p.d }}$ foi de 41,59 (Figura 12).

TABELA 5 - Valores de eficiência de remoção (E), taxa de utilização $\left(\tau_{\mathrm{u}}\right)$ e potencial de remoção $\left(m_{\mathrm{Ps} \text {, máx }}\right)$ do experimento operando com TDS $=5$ d em uma fase anaeróbia e uma fase aeróbia tratando o efluente do equalizador (4a) e o efluente do reator UASB (4b) de uma indústria de parboilização

\begin{tabular}{cccc}
\hline Tratamento & $\mathrm{E}(\%)$ & $\tau_{\mathrm{u}}(\%)$ & $\boldsymbol{m}_{\mathrm{Ps}, \text { max }}(\mathbf{m g})$ \\
\hline $4 \mathrm{a}$ & 6,90 & 21,76 & 71,58 \\
$4 \mathrm{~b}$ & 17,82 & 48,78 & 85,26 \\
\hline
\end{tabular}

Os valores de $m_{\mathrm{Ps} \text {, máx }}$ mostram que um descarte maior de lodo poderá aumentar a remoção de fósforo para os dois tratamentos (Tabela 5).

A maior eficiência obtida no tratamento $4 \mathrm{~b}$, tratando o efluente do UASB, comparada ao tratamento $4 \mathrm{a}$, tratando o efluente do equalizador, está em desacordo com a literatura [21], que cita que relações DQO/P e AVT/P maiores favorecem a eficiência do processo. A baixa eficiência do tratamento 4a deve-se à utilização de TDS de cinco dias e à alta carga orgânica do efluente, o que acarretou uma elevada relação substrato/microorganismo pelo grande descarte de biomassa, desestabilizando o processo.

\section{4 - CONCLUSÕES}

O cálculo da eficiência de sistemas biológicos estimulados para remoção de fósforo deve ser feito pela relação entre a massa de fósforo suspenso descartada e a massa total de fósforo alimentada.

O maior potencial de remoção de fósforo $\left(m_{\mathrm{Ps} \text {, máx }}=46,14\right.$ mg) ocorreu no processo operando com uma fase anaeróbia e uma fase aeróbia por ciclo, com a adição de HAc.

O tempo de reação de um dia tem a maior possibilidade de aumento da eficiência pelo incremento do descarte de biomassa.

O sistema, operando em tempos de detenção de sólidos menores, obtém as maiores eficiências de remoção de fósforo.

A capacidade de remoção de fósforo é melhor utilizada com tempo de detenção de sólidos de cinco dias.

A maior eficiência $(E=17,82 \%)$ foi obtida no experimento que operou tratando o efluente do reator UASB com TDS de cinco dias, com um ciclo constituído de uma fase anaeróbia de 2 h, uma fase aeróbia de 5 h e tempo de decantação de 30 min, sem a adição de fonte externa de carbono.

A remoção de fósforo do efluente da parboilização de arroz poderá ser complementada através de um processo de precipitação química. 


\section{5 - REFERÊNCIAS BIBLIOGRÁFICAS}

[1] ABIAP. Dados Estatísticos no Brasil. In: . Dados Estatísticos. Porto Alegre: 2001. Disponível em: http://www.abiap.com.br/DadosBrasil.php. Acesso em: 9 dez. 2004.

[2] ANCHENG LUO, J.Z.; NDEGWA, P.M. Influence of anaerobic pre-conditioning on phosphorus removal in swine manure by aeration. Water, Air and Soil Pollution, [Amsterdam], v. 140, n. 1, p. 219-230, 2002.

[3] APHA - AMERICAN PUBLIC HEALTH ASSOCIATION. Standard methods for the examination of water and wastewater. $20^{\text {th }}$. Washington: Public Health Assoc., 1998.

[4] BAUMGARTEN, M.G.Z. \& POZZA, S.A.; Qualidade de águas: descrição de parâmetros químicos referidos na legislação ambiental. Rio Grande: Furg, 2001,166 p.

[5] BELITZ, H.; GROSCH, W. Química de los alimentos. Zaragoza: Acríbia, 1988, 549 p.

[6] BRASIL. IBGE. Levantamento Sistemático da Produção Agrícola. In:_. Indicadores. [S.1.]: 2003. Disponível em: http://www.ibge.gov.br/home/estatistica/indicadores/agropecuaria/lspa/lspa09200405.shtm. Acesso em: 9 dez. 2004.

[7] BRASIL. Portaria $\mathrm{n}^{\circ} 269$, de 17 de novembro de 1988. Norma de Identidade, Qualidade, Embalagem e Apresentação do Arroz. Diário Oficial [da] República Federativa do Brasil, Ministério da Agricultura, Pecuária e Abastecimento, Brasília (DF), 22 nov. 1988. Seção 1, p. 22.531.

[8] CHEN, Y.; RANDALL, A.A.; McCue, T. The efficiency of enhanced biological phosphorus removal from real wastewater affected by different ratios of acetic to propionic acid. Water Research, [London], v. 38, n. 1, p. 27-36, 2004.

[9] COBALCHINI, M.S. et al. Análise da norma de padrões de emissão de efluentes líquidos do RS: Dificuldades no seu cumprimento e propostas. In: Silubesa - Simpósio Luso-Brasileiro de Engenharia Sanitária e Ambiental, IX, 2000, Porto Seguro. Anais... Porto Seguro: ABES, 2000, p. 2.108-2.121.

[10] CROCETTI, G.R. et al. Identification of polyphosphateaccumulating organisms and design of 16S rRNA-directed probes for their detection and quantification. Applied Enviromn Microbiology, [S.1.], v. 66, n. 3, p. 1.175-1.182, 2000

[11] ELIAS, M.C. et al. Operações hidrotérmicas na parboilização de arroz agulhinha: irrigado. Revista da Sociedade Brasileira de Ciência e Tecnologia de Alimentos, Campinas, v. 16, n. 3, p. 1.908$1.911,1998$

[12] FENNEMA, O.R. Introducción a la ciencia de los alimentos. [S.1.]: Reverté, 1982. 401 p.

[13] GUTKOSKI, L.C. Efeitos das condições de maceração e de autoclavagem na qualidade industrial e comercial dos grãos de arroz (Oryza sativa L.) parboilizados. 1991. 122 p. Dissertação (mestrado em Ciência e Tecnologia Agroindustrial) - DCTA, Faem, Universidade Federal de Pelotas, Pelotas, 1991.

[14] HOSENEY, R.C. Principios de ciência y tecnologia de los cereales. Zaragoza: Acríbia, 1991. 321 p.
[15] LetTINGA, G.; VAN HAANDEL, A. Tratamento Anaeróbio de Esgotos: Um manual para regiões de clima quente. Campina Grande: Epgraf, 1994. Paginação irregular.

[16] LIMA, E.P.P. Pós-tratamento em reator com recheio de pedra calcária de efluentes da parboilização do arroz tratados em reator UASB. 2003. 42 p. Dissertação (mestrado em Ciência e Tecnologia Agroindustrial) - DCTA, Faem, Universidade Federal de Pelotas, Pelotas, 2003.

[17] LOPES, L.F.; KOETZ, P.R. \& SANTOS, M.S. Denitrificação no topo de reator UASB, de efluentes da indústria de arroz parboilizado. In: Oficina e Seminário Latinoamericano de Digestão Anaeróbia, VI, 2000, Recife. Anais... Recife: UFPE, 2001, p. 5-9.

[18] METCALF \& EDDY, Inc. Wastewater engineering: treatment and reuse. $4^{\text {th }}$ ed. rev. New York: McGrawHill, 2003, 1.758 p. ISBN 0-07-041878-0.

[19] OKUNUKI, S. et al. Changes in phosphorus removing performance and bacterial community structure in an enhanced biological phosphorus removal reactor. Water Research, [London], v. 38, n. 9, p. 2.433-2.439, 2004.

[20] RANDALL, C.W.; BARNARD, J.L.; STENSEL, H. D. Design and retrofit of wastewater treatment plants for biological nutrient removal. Lancaster: Technology Publishing, 1992.

[21] REDDY, M. (Chair). Biological and chemical systems for nutrient removal: a special publication. Alexandria: WEF, 1998, 399 p. ISBN 1-57278-123-8.

[22] RIO GRANDE DO SUL (Estado). Portaria $n^{\circ} 05 / 89$, de 16 de março de 1989. Aprova a norma técnica SSMA n ${ }^{\circ}$ 01/89 - DMA, que dispõe sobre critérios e padrões de efluentes líquidos a serem observados por todas as fontes poluidoras que lancem seus efluentes nos corpos d'água interiores do estado do Rio Grande do Sul. Diário Oficial [do] Estado, Secretariada da Saúde e do Meio Ambiente, Porto Alegre (RS), 29 mar. 1989.

[23] SANTOS, M.S. Pós-tratamento físico-químico e biológico de efluentes da parboilização do arroz tratados em reator UASB. 2003. 46 p. Dissertação (mestrado em Ciência e Tecnologia Agroindustrial) - DCTA, Faem, Universidade Federal de Pelotas, Pelotas, 2003.

[24] SCHULZ, C.K. Remoção biológica de carbono do efluente da parboilização do arroz utilizando reatores EGSB. 2000. Dissertação (mestrado em Ciência e Tecnologia Agroindustrial) - DCTA, Faem, Universidade Federal de Pelotas, Pelotas, 2000.

[25] SEDLAK, R. Phosphorus and nitrogen removal from municipal wastewater. New York: Lewis, 1991, 240 p.

[26] VAN HAANDEL, A.; MARAIS, G. O comportamento do sistema de lodo ativado: Teoria e Aplicações para Projetos e Operação. Campina Grande: Epgraf, 1999, 472 p. ISBN 900-847.

\section{6 - AGRADECIMENTOS}

Agradecemos a Capes, ao CNPq e a Fapergs pelo financiamento e as empresas Nelson Wendt Alimentos e Sanitec pelo apoio. 